\title{
The acute effects of repeated static apnea on aerobic power
}

\author{
Yildiz M. ${ }^{A B C D E}$
}

${ }^{1}$ School of Physical Education and Sports, Afyon Kocatepe University, Turkey

Authors' Contribution: A - Study design; B - Data collection; C - Statistical analysis; D - Manuscript Preparation; E - Funds Collection

\begin{abstract}
Purpose: $\quad$ Apnea exercises cause a rise in hematocrit, erythropoietin, hemoglobin concentration, lung volume and oxygen store in muscle and blood, and a decrease in blood acidosis and oxidative stress. These types of physiological changes that occur in the body result in developments in both time to exhaustion and V02max. The purpose of the current study was to investigate the acute effect of repeated static apneas on aerobic power.

Material: $\quad$ Twenty physically active male university students (age:22.80 \pm 3.84 year, height:177.40 \pm 7.49 cm and weight: $68.20 \pm 8.72 \mathrm{~kg}$ ) volunteered to participate in the current study. They were divided as the static apnea and control groups randomly. The static group performed multistage exercise treadmill test to exhaustion (maximal aerobic power) after three maximal apneas with 2-min interval in sitting position. The control group performed only the maximal aerobic power test without apnea. Their maximal oxygen consumption (Vo2max), gas exchange rate (RER), heart beat rate (HR) and rate of perceived exertion (RPE) values were measured during maximal aerobic test. Their hemoglobin $(\mathrm{Hb})$ and hematocrit $(\mathrm{Hct})$ values were measured before and immediately after the apnea for both groups.

Results: $\quad$ There were no significant differences found between the control and static apnea groups for Vo2max, HR, Hb and Hct. However, RPE values measured after the static apnea were lower (17.55 \pm 0.51$)$ than the control (18.75 \pm 0.62$)$.

Conclusions: The repeated static apneas immediately prior the maximal aerobic effort cannot increase aerobic power in untrained breath hold participants. However, the lower RPE after static apnea may be used as an ergogenic effect.

Keywords: $\quad$ Hypoxia- Static, Apnea, Respiratory, Exchange, Ratio, Rate of Perceived, Exertion, Hemoglobin, Hemotocrite.
\end{abstract}

\section{Introduction}

Hypoxia is defined as a decrease in oxygen $\left(\mathrm{O}_{2}\right)$ availability. It occurs with ascent to altitude. Exposure to hypoxia leads to considerable challenges in the cardiovascular and respiratory systems and hematological adjustments (related to the $\mathrm{O}_{2}$ transport capacity of the blood). Both acute and chronic exposure to hypoxia increases erythropoietin concentration (EPO) [1, 2, 3]. Increased EPO concentration triggers erythrocyte production. An increase in erythrocyte leads to an increase in circulating reticulocytes, hemoglobin concentration $(\mathrm{Hb})$, hematocrit $(\mathrm{Hct})$ and red blood cell (RBC) mass [2]. Similarly, apnea (breath holding) affects a lot of physiological processes in the human body as well. The most important physiological effects of apnea on the human body are the altered hemodynamics, and apnea induced splenic contraction [4]. Long term apnea exercises cause a rise in Hct, EPO, Hb mass, lung volume $[5,6,7]$, and oxygen stores in muscle (myoglobin) and blood, and a decrease in blood acidosis and oxidative stress $[8,9]$. Moreover, an increase in the total amount of $\mathrm{RBC}$ is predominantly synthesized by the kidneys in response to the chronic apnea $[2,10]$.

There are also some studies focusing on the acute effect of repeated apneas on human physiology [11, 12, 13]. According to these studies, repeated apneas (2min intervals) cause splenic contraction. Thus, Hct and $\mathrm{Hb}$ are increased independently [14], arterial oxygen desaturation is decreased, and apnea duration is prolonged $[13,14,15$,$] . The average human spleen has a blood$ reserve of approximately $200-250 \mathrm{ml}$, and if triggered, it can typically increase the total number of circulating RBC by $2-4 \%$ [16]. Furthermore, it has been indicated that repeated apnea triggers hypoxemia in the kidney (c) Yıldız M., 2018

doi:10.15561/20755279.2018.0407 and spleen, and increase Hct and $\mathrm{Hb}$ and serum EPO, respectively [11]. However, these increments in Hct and $\mathrm{Hb}$ generally last around ten minutes $[11,12,13]$.

It is well known that aerobic performance in sport is highly dependent on $\mathrm{V}_{02 \max }$ which reflects the ability to maximally uptake, transport and utilize of $\mathrm{O}_{2}$. Moreover, there is a close correlation between $\mathrm{V}_{02 \max }$ ability and factors that contribute to the availability of oxygen such as $\mathrm{Hb}$ and Hct $[17,18,19]$. Previously, it has been demonstrated that increments in $\mathrm{Hb}$ and Hct result in developments in both time to exhaustion and $\mathrm{V}_{02 \max }[20]$.

These findings support that apnea exercises may have ergogenic effects on aerobic power in human. Because the major determinant of aerobic performance depends on the capacity of transport oxygen to the tissues [21]. Repeated apneas may play an important role in $\mathrm{O} 2$ availability to enhance $\mathrm{O} 2$ transport to the body by inducing splenic contraction and increasing $\mathrm{Hb}$ and Hct. [11, 12, 22]. Therefore, the question arises as to whether aerobic power of participants can be improved by repeated static apneas immediately prior to the maximal aerobic effort.

The aim of the present study was to investigate the acute effects of static repeated apnea exercises on aerobic power.

\section{Materials and Methods}

Subjects

Twenty physically active male university students (age:22.80 \pm 3.84 , height:177.40 \pm 7.49 and weight:68.20 \pm 8.72 ) volunteered to participate in the current study. All participants had no health history of cardiovascular, metabolic or pulmonary and spleen disease and had no history of sleep apnea. Moreover, participants had no previous apnea experience (e.g. free divers, under water rugby players or synchronized swimmers). 
They had no significant altitude experience $(\geq 2,000 \mathrm{~m}$. for more than one week) for at least six months prior to the participation in the study. The study was approved by the local ethics committee of the university. It was in accordance with the ethical standards of the Helsinki Declaration. Each participant signed the written informed consent before the start of the study.

\section{Experimental Design}

To examine the effects of repeated apneas on aerobic power, participants were divided as control and static apnea groups randomly. The static group performed multistage exercise treadmill test according to the Bruce protocol to exhaustion after three maximal apneas with 2-min interval in sitting position. The control group performed the same test without an apnea intervention.

\section{Measurements}

Participants' hemoglobin $(\mathrm{Hb})$ and hematocrit (Hct) values were obtained before and immediately after the static apnea protocol and from the control group. Their maximal oxygen consumption $\left(\mathrm{V}_{\mathrm{O} 2 \max }\right)$, gas exchange values (RER), heart beat rate (HR), and the rate of perceived exertion (RPE) values were obtained during maximal aerobic power test for both groups. The multistage exercise treadmill test according to the Bruce protocol was used as an aerobic power test.

$\mathrm{V}_{\mathrm{O} 2 \max }$ and the gas exchange values were measured with a respiratory gas exchange analyzer VO2000 (Medgraphic, USA). Heart beat rate was determined with a heart rate monitor (Polar Vantage NVt, Polar Electro Oy, Kempele, Finland). The rate of perceived exertion from 6 to 20 (RPE) was calculated according to the Borg scale [23]. Venous blood samples were collected from the right cubital vein for determination of $\mathrm{Hb}$ and Hct. Analyses were carried out with Celldyn 3500 automated hematology analyzer (Abbott, USA) at the Biochemistry laboratory of the state Hospital.

\section{Repeated apnea protocol}

After a 10-min of warm-up exercise which included cycling on a bicycle ergometer and free stretching, participants were familiarized with static apnea exercises. We wanted the participants to hold their breath for maximally during familiarization session to ensure a participant was able to reach required breath hold time during static apnea. The minimal cut off criteria for breath hold duration was $90 \%$ of each participant static apnea time measured during familiarization testing. External encouragement and information was provided to the approach for maximal apnea time and maximal aerobic power test. During a 10 seconds pre-trial, a nose clip was attached to the participants. The participants took a few deep breaths (not maximal) prior inhalation to total lung capacity. After that, we wanted the participants to hold their breath for maximally three times.

Each apnea was separated by a 2-min rest and normal breathing. During all 2-min of rests, the nose clip was removed. A 2-min rest after the maximal apnea protocols, the participants performed a multistage incremental test to exhaustion on the treadmill. External encouragement and information was provided to the approach for maximal apnea time and $\mathrm{V}_{\mathrm{O} 2 \max } . \mathrm{V}_{\mathrm{O} \text { max }}$ achievement criteria: RER $>1.10$; HR $>90 \%$; less than $100 \mathrm{~mL} \cdot \mathrm{min}^{-1}$ change in $\mathrm{VO}_{2}$ (over two consecutive minutes).

\section{Data Analysis}

SPSS for Windows version 18.0 was used to analyze the obtained data. Besides mean and standard deviation of values, repeated measures analysis of variance (ANOVA) test was used to compare measurements for $\mathrm{Hb}$ and Hct. When the assumptions of sphericity were violated, a Greenhouse-Geisser adjustment was used. To identify significant differences between pairs of measurements a Bonferroni post hoc test was used. An independent t test was used to compare the $\mathrm{V}_{\mathrm{O} 2 \max }$, RER, HR, RPE values of two groups. The alpha level was set at 0.05 .

\section{Results}

Table 1 shows the means and SDs of the apnea duration.

Table 2 shows the means and SDs of the $\mathrm{V}_{\mathrm{O} 2 \max }$, HR, RER and RPE results of two trials from the same participants. There were no significant differences found between protocols for $\mathrm{V}_{\mathrm{O} 2 \max }$, and $\mathrm{HR}$, RER results. However, the RPE results measured after the static apnea were lower (17.55 \pm 0.51$)$ than the control (18.75 \pm 0.62$)$.

Table 3 outlines the means and SDs of the $\mathrm{Hb}$ and Hct results. There were no significant differences found with regard to $\mathrm{Hb}$ and Hct results.

Table 1. means \pm standard deviation of apnea duration

\begin{tabular}{ll}
\hline & $\bar{X}_{ \pm}$Sd \\
\hline First apnea (sec) & $71.05 \pm 7.12$ \\
Second apnea (sec) & $73.70 \pm 7.43$ \\
Third apnea (sec) & $71.75 \pm 6.31$ \\
\hline
\end{tabular}

$\bar{X}=$ Mean, $\mathrm{Sd}=$ Standart deviation

Table 2. Effects of repeated static apneas on $\mathrm{VO}_{2}$ max, $H R, R E R, R P E$ results (means \pm standard deviation)

\begin{tabular}{lcc}
\hline & CON & SA \\
\hline $\mathrm{VO}_{2} \max (\mathrm{ml} / \mathrm{kg} / \mathrm{min}$ & $55.18 \pm 5.79$ & $57.20 \pm 4.92$ \\
$\mathrm{HR}(\mathrm{bpm})$ & $191 . .01 \pm 6.40$ & $192.10 \pm 5.44$ \\
$\mathrm{RER}$ & $1.24 \pm 0.05$ & $1.29 \pm 0.51$ \\
$\mathrm{RPE}$ & $18.75 \pm 0.62$ & $17.55 \pm 0.51^{*}$ \\
\hline
\end{tabular}

$*=p<0.05, \mathrm{CON}=$ Control, SA= Static Apnea, HR= heart rate, $\mathrm{RER}=$ Respiratory Exchange Ratio, $\mathrm{RPE}=$ Rate of Perceived Exertion

Table 3. Effects of repeated static apneas on $\mathrm{Hb}$ and $\mathrm{Hct}$ results (means \pm standard deviation)

\begin{tabular}{lll}
\hline & CON & SA \\
\hline $\mathrm{Hb}(\mathrm{g} \mathrm{dL}-1)$ & & \\
Baseline & $14.39 \pm 1.01$ & $14.68 \pm 0.92$ \\
$\begin{array}{c}\text { Post-apnea } \\
\text { Hct (\%) }\end{array}$ & $14.21 \pm 0.91$ & $15.28 \pm 1.02$ \\
$\quad$ Baseline & $45.24 \pm 1.74$ & $46.06 \pm 1.65$ \\
Post-apnea & $45.12 \pm 1.61$ & $46.86 \pm 1.78$ \\
\hline
\end{tabular}

$\mathrm{CON}=$ Control, $\mathrm{SA}=$ Static Apnea, $\mathrm{Hb}=$ Hemoglobin $\mathrm{Hct}=$ Hematocrit 


\section{Discussion}

In the current study, we investigated the acute effects of the repeated static apneas on aerobic power. There were no significant differences found for $\mathrm{V}_{\mathrm{O} 2 \max }$, $\mathrm{HR}, \mathrm{RER}, \mathrm{Hb}$ and Hct results. However, the RPE values measured after the static apnea was lower than the control group.

There are limited studies investigating repeated apnea and aerobic performance in the literature. Similar to the present study, Sperlich et al. investigated whether acute repeated four maximal apneas with 2-min recovery improve a $4-\mathrm{km}$ time trial performance of cyclists. They found no significant difference in mean power [26]. These results are similar to the outcomes obtained in the study of $\mathrm{Du}$ Bois who demonstrated no significant difference in $\mathrm{V}_{\mathrm{O} \text { max }}$ and in time to exhaustion test [4]. Many studies have determined that performing repeated apneas increases $\mathrm{Hb}[27,11,12,28]$, Hct [14, 29, 27, 15, 28], and $\mathrm{RBC}$ [14] by inducing spleen contraction in the trained and untrained breath hold subjects. However, Bakovic et al. did not find any significant change in untrained breath hold participants [14]. These results are consistent with the findings of the current study considering that the participants of the present study were untrained breath hold subjects. In contrast to the current study, Lemaitre et al. determined an enhanced maximal and submaximal swimming performance after long-term apnea exercises because of the improved $\mathrm{M}_{\text {axvo2 }}$ [31]. It means that apnea during several weeks of training may enhance performance. Therefore, it is likely that adaptation of the body to the repeated apnea induced increments in $\mathrm{Hb}$, Hct and aerobic power occurs as a result of the long-term apnea training.

The Rating Scale of Perceived Exertion (RPE) is used extensively as a psycho-physical method during the exercise to determine subjective perception of effort. It has been suggested by the American College of Sports Medicine for monitoring exercise intensity to add precision to heart rate [32]. Therefore, it can be used as an inexpensive and valid method to monitor an intensity of the exercise [33]. Another significant change reported in the current study was that SA demonstrated significantly lower RPE value than CON trial. A hypothesis explaining these findings could be that the participants mostly stimulated anaerobic glycolysis during the SA trial. Because there is a high relationship (quadratic regression $=0.84, \mathrm{p}<0.001$ ) between RPE and blood lactate [33]. Previous research reported that when a human enters the last stages of the static apneas, oxygen saturation decreases $[30,34,35,36]$. A decrease of oxygen saturation can last at least two minutes before the full recovery [30]. In the present study, there was only a 2-min rest between the repeated apneas and the multistage incremental exercise test. It is possible that the participants began the trial to exhaustion with the full recovery position. Moreover, starting the test at the low intensity level might trigger the body to consume more oxygen because of oxygen deficit during the repeated apnea trials. This situation might decrease RPE values in the repeated apnea group when compared with the control group.

\section{Conclusion}

In the current study, we investigated the acute effects of repeated static apnea exercise on aerobic power. There were no significant differences detected between protocols for VO2max, HR, RER, $\mathrm{Hb}$ and Hct results. However, the RPE values measured after the static apnea trial was lower than the control trial. The repeated static apnea prior the maximal aerobic effort cannot increases aerobic power in untrained breath hold participants. The lower rate of perceived exertion may be used as an ergogenic effect.

\section{Conflict of Interests}

The author declare that there is no conflict of interest regarding the publication of this paper.

\section{Reference}

1. Ge RL, Witkowski S, Zhang Y, et al. Determinants of erythropoietin release in response to short-term hypobaric hypoxia. J.Appl.Physiol. 2002; 92(6):2361-2367.

2. Jelkmann W. Erythropoietin: structure, control of production, and function. Physiol.Rev. 1992; 72(2):449-489.

3. Knaupp W, Khilnani S, Sherwood J, Scharf S, Steinberg H. Erythropoietin response to acute normobaric hypoxia in humans. J.Appl.Physiol. 1992; 73(3): 837-840.

4. Du Bois AM, Nelson GC, Ciccone AB, et al. Effect Of Serial Apneas And Facial Immersion On High Intensity Aerobic Performance. Medicine \& Science in Sports \& Exercise, 2014; 46(5S):701

5. De Bruijn R, Richardson M, Schagatay E. Increased erythropoietin concentration after repeated apneas in humans. Eur J Appl Physiol. 2008; 102:609-13.

6. Schagatay E, Andersson JP, Nielsen B. Hematological response and diving response during apnea and apnea with face immersion. Eur J Appl Physiol. 2007; 101:125-32.

7. Nygren-Bonnier M, Gullstrand L, Klefbeck B, et al. Effects of glossopharyngeal pistoning for lung insufflation in elite swimmers. Med Sci Sports Exerc. 2007; 39:836-41.

8. Joulia F, Steinberg JG, Faucher M, et al. Breath-hold training

of humans reduces oxidative stress and blood acidosis after static and dynamic apnea. Respir Physiol Neurobiol. 2003; 137:19-27.

9. Joulia F, Steinberg JG, Wolff F, et al. Reduced oxidative stress and blood lactic acidosis in trained breath-hold human divers. Respir Physiol Neurobiol. 2002; 133:121-30.

10.Lemaitre F, Joulia F, Chollet D. Apnea: A new training method in sport? Medical hypotheses. 2010; 74(3): 413-415.

11.Richardson M, De Bruijn R, Holmberg HC, Bjorklund G, Haughey H, Schagatay E. Increase of hemoglobin concentration after maximal apneas in divers, skiers, and untrained humans. Can.J.Appl.Physiol. 2005; 30(3):276-281.

12.Richardson MX, De Bruijn R, Schagatay E. Hypoxia augments apnea induced increase in hemoglobin concentration and hematocrit. Eur.J.Appl.Physiol. 2009; 105(1):63-68.

13.Schagatay E, Haughey H, Reimers J. Speed of spleen volume changes evoked by serial apneas. Eur JAppl Physiol. 2005; 93:447-452

14.Bakovic D, Eterovic D, Saratlija-Novakovic Z, et al. Effect of human splenic contraction on variation in circulating blood cell counts. Clin Exp Pharmacol Physiol. 2005; 32:944-51.

15.Prommer N, Schmidt W. Loss of CO from the intravascular bed and its impact on the optimised CO-rebreathing method. 
Eur.J.Appl.Physiol. 2007; 100(4):383-391.

16.Richardson MX, Lodin A, Reimers J, Schagatay E. Shortterm effects of normobaric hypoxia on the human spleen. Eur.J.Appl.Physiol. 2008; 104(2):395-399.

17.Abbiss CR, Laursen PB Models to explain fatigue during prolonged endurance cycling. Sports Med. 2005; 35:865898.

18. Heinicke K, Wolfarth B, Winchenbach P, et al. Blood volume and hemoglobin mass in elite athletes of different disciplines. Int J Sports Med. 2001; 22:504-512.

19.Marx JJ, Vergouwen PC Packed-cell volume in elite athletes. Lancet. 1998; 352(9126):451.

20.Kanstrup IL, Ekblom B. Blood volume and hemoglobin concentration as determinants of maximal aerobic power. Med Sci Sports Exerc. 1984; 16:256-262.

21.Brugniaux JV, Schmitt L, Robach P, et al. Eighteen days of "living high, training low" stimulate erythropoiesis and enhance aerobic performance in elite middle-distance runners. J Appl Physiol. 2006; 100:203-11.

22.Foster GE, Sheel AW. The human diving response, its function, and its control. Scand.J.Med.Sci.Sports. 2005; 15:(1)3-12.

23. Borg GA. Psychophysical bases of perceived exertion. Med sci sports exerc, 1982; 14(5):377-381.

24.Lemaitre F, Polin D, Joulia F, et al. Physiological responses to repeated apneas in underwater hockey players and controls. Undersea Hyperb Med. 2007; 34(6):407.

25.Andersson JP, Linér MH, Jönsson $\mathrm{H}$. Increased serum levels of the brain damage marker S100B after apnea in trained breath-hold divers: a study including respiratory and cardiovascular observations. J Appl Physiol. 2009; 107(3):809-815.

26. Sperlich B. Repeated apnea-induced contraction of the spleen in cyclists does not enhance performance in a subsequent time-trial. European journal of applied physiology, 2015; 115(1): 205-212.

27.Hurford WE, Hong SK, Park YS, et al. Splenic contraction during breath-hold diving in the Korean ama. J Appl Physiol. 1990; 69:932-936.

28. Andersson J, Schagatay E. Arterial oxygen desaturation during apnea in humans. Undersea Hyperb Med. 1998; 25(1), 21.

29.Espersen K, Frandsen H, Lorentzen T, Kanstrup IL, Christensen NJ. The human spleen as an erythrocyte reservoir in diving-related interventions. J Appl Physiol. 2002; 92(5):2071-2079.

30.Baković D, Valic Z, Eterović et al. Spleen volume and blood flow response to repeated breath-hold apneas. J Appl Physiol. 2003; 95(4):1460-1466.

31.Lemaitre F, Seifert L, Polin D, et al. Apnea training effects on swimming coordination. J Strength Cond Res/Natl Strength Cond Assoc. 2009; 23:1909-1914.

32.American College of Sports Medicine ACSM's guidelines for exercise testing and prescription. Baltimore: Lippincott Williams \& Wilkins; 2009.

33.Scherr J, Wolfarth B, Christle JW, Pressler A, Wagenpfeil S, Halle M. Associations between Borg's rating of perceived exertion and physiological measures of exercise intensity. Eur.J.Appl.Physiol. 2013; 113(1):147-155.

34.Guaraldi P, Serra M, Barletta G, et al. Cardiovascular changes during maximal breath-holding in elite divers. ClinAuton Res. 2009; 19:363-366.

35.Palada I, Eterovic D, Obad A, et al. Spleen and cardiovascular function during short apneas in divers. JAppl Physiol. 2007; 103:1958-1963.

36. Rodriguez FA, Ventura JL, Casas M, et al. Erythropoietin acute reaction and haematological adaptations to short, intermittent hypobaric hypoxia. Eur.J.Appl.Physiol. 2000; 82(3):170-177.

37.Powers CK, Howley ET. Exercise Physiology (Theory and application to fitness and performance). USA: McGraw-Hill International edition; 2011.

38.Hoffman J. Physiological aspects of sport training and performance. Human Kinetics; 2014.

\section{Information about the author:}

Yıldız M. http://orcid.org/0000-0003-3481-7775; mehmetyildiz@aku.edu.tr; School of Physical Education and Sports, Afyon Kocatepe University; Afyonkarahisar 03200, Turkey.

Cite this article as: Yildiz M. The acute effects of repeated static apnea on aerobic power. Physical education of students, 2018;22(4):217-220. doi:10.15561/20755279.2018.0407

The electronic version of this article is the complete one and can be found online at: http://www.sportedu.org.ua/index.php/PES/issue/archive

This is an Open Access article distributed under the terms of the Creative Commons Attribution License, which permits unrestricted use, distribution, and reproduction in any medium, provided the original work is properly cited (http://creativecommons.org/licenses/by/4.0/deed.en).

Received: 25.06.2018

Accepted: 16.07.2018; Published: 23.08.2018 